\title{
A transition-phase teleconnection of the Pacific quasi-decadal oscillation
}

\author{
Shih-Yu Wang • Robert R. Gillies • \\ Lawrence E. Hipps $\cdot$ Jiming Jin
}

Received: 24 June 2009/Accepted: 3 December 2009/Published online: 12 January 2010

(C) The Author(s) 2010. This article is published with open access at Springerlink.com

\begin{abstract}
The atmospheric circulation patterns associated with the Pacific quasi-decadal oscillation (QDO) are investigated using available observational data from 1948 to 2007. Previous studies indicate that the Pacific QDO is characterized by a distinct lifecycle in the form of sea surface temperature (SST) patterns. In the warm and cool phases of the Pacific QDO, the SST patterns resemble those associated with the El Niño-Southern Oscillation (ENSO). During the warm-cool and cool-warm transitions of the Pacific QDO, recurrent SST patterns are also clearly visible. The rotated empirical orthogonal function analysis on the 10-15 year filtered data shows that the evolutions of SST and atmospheric circulation are well coupled. While the warm-/cool-phase Pacific QDO generates an ENSOlike circulation pattern, the transition phases form a distinct short-wave train emanating from Southeast Asia towards North America. This short-wave train is particularly robust in the streamfunction of water vapor flux. Diagnostic analyses of the heat budget, the stationary wave flux, and a barotropic model indicate that this short-wave train is
\end{abstract}

Electronic supplementary material The online version of this article (doi:10.1007/s00382-009-0722-5) contains supplementary material, which is available to authorized users.

S.-Y. Wang $(\bowtie) \cdot R$. R. Gillies

Utah Climate Center, Utah State University, 4825 Old Main Hill, Logan, UT 84322-4825, USA

e-mail: simon.wang@usu.edu

R. R. Gillies · L. E. Hipps · J. Jin

Department of Plants, Soils, and Climate,

Utah State University, Logan, UT, USA

J. Jin

Department of Watershed Sciences,

Utah State University, Logan, UT, USA thermodynamically maintained and is likely forced by diabatic heating near Southeast Asia. Additional modulations of forcing sources in the western and eastern tropical Pacific on this short-wave teleconnection are also discussed.

Keywords Pacific QDO - Teleconnection - Wave train . Transition phase

\section{Introduction}

The sea surface temperature (SST) variations in the tropical Pacific Ocean occur at various time scales ranging from biennial to multi-decadal (e.g., Philander 1990; Trenberth 1990; Allan 2000; Minobe 2000; Mantua and Hare 2002). The same variation frequencies also characterize the atmospheric teleconnection patterns induced from the tropical Pacific (Nakamura et al. 1997; Zhang et al. 1997; Enfield and Mestas-Nuñez 1999; Barlow et al. 2001; Wu et al. 2003; Chen et al. 2008), as well as the global hydrological cycle affected by those teleconnection patterns (Dettinger et al. 2000; Meinke et al. 2005, and others). A growing literature which focused on the lowfrequency SST variability in the tropical Pacific identified a quasi-decadal oscillation (QDO) known as the Pacific QDO. The frequency of the Pacific QDO ranges between 9 and 13 years (Allan 2000; Tourre et al. 2001) or 10 and 15 years (Wang et al. 2009a, b, hereafter WGJH). Recent studies (e.g., White and Tourre 2003; White and Liu 2008a) proposed that the Pacific QDO is likely formed by the solar irradiance cycle through a delayed action/recharge process, similar to the process that drives El Niño/La Niña (Jin 1997) but with an expanded latitude range (White et al. 2003a, b; Fyfe and Saenko 2007). The Pacific QDO also 
appears to modulate the biennial activity of the El NiñoSouthern Oscillation (ENSO) (White and Liu 2008b).

The Pacific QDO reveals a complete lifecycle with distinctive phases in terms of the SST and sea level pressure (SLP) patterns. During the extreme phases of the Pacific QDO (i.e. warm and cool), an ENSO-like SST pattern emerges characterized by extensive warming/ cooling areas in the central tropical Pacific (Zhang et al. 1997; Allan 2000; Tourre et al. 2001) and, exhibits largest variability in the NINO4 region (domain indicated in Fig. 1). This feature is dissimilar to the typical ENSO modes in the quasi-biennial and interannual frequencies in which the SST anomalies prevail in the NINO3 region and are more confined tropically (e.g., Enfield and MestasNuñez 1999; Lohmann and Latif 2005). During the warmcool and cool-warm transitions of the Pacific QDO, the SST anomalies in the central tropical Pacific become weak; however, recurrent SST patterns appear with noticeable anomalies in the western and eastern tropical Pacific accompanied by strong SLP anomalies in the midlatitudes (Tourre et al. 2001; White and Tourre 2003; White and Liu 2008b). While the atmospheric circulation patterns associated with the warm/cool phases of the Pacific QDO and the positive/negative phases of the Pacific Decadal Oscillation have been thoroughly explored (e.g., Chen et al. 2008), what has not been addressed is whether an atmospheric teleconnection may form in response to the SST pattern of the transition-phase Pacific QDO. The teleconnection, if it exists, may be important for some regions where the regional precipitation variations reveal strong quasi-decadal signals but are not directly correlated with the Pacific QDO.

The central Intermountain West of the United States is one such example. Elevational variations of the Great Salt Lake, located near the center of this region, feature a pronounced 12 year signal (Lall and Mann 1995; Mann et al. 1995) and are found to be highly coherent with the

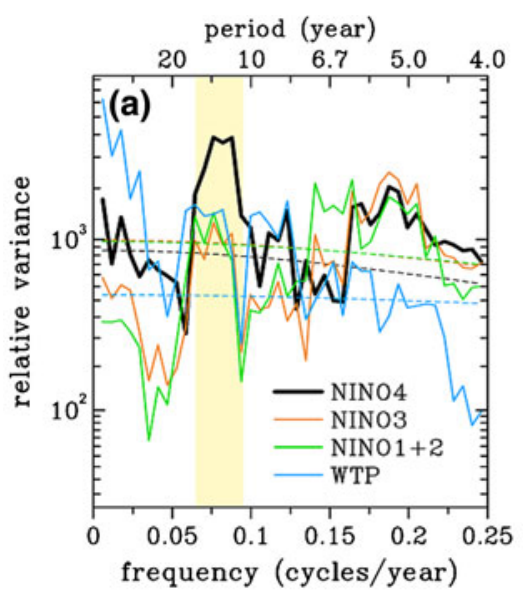

(c) REOF $1[\mathrm{SST}] 51.2 \%$

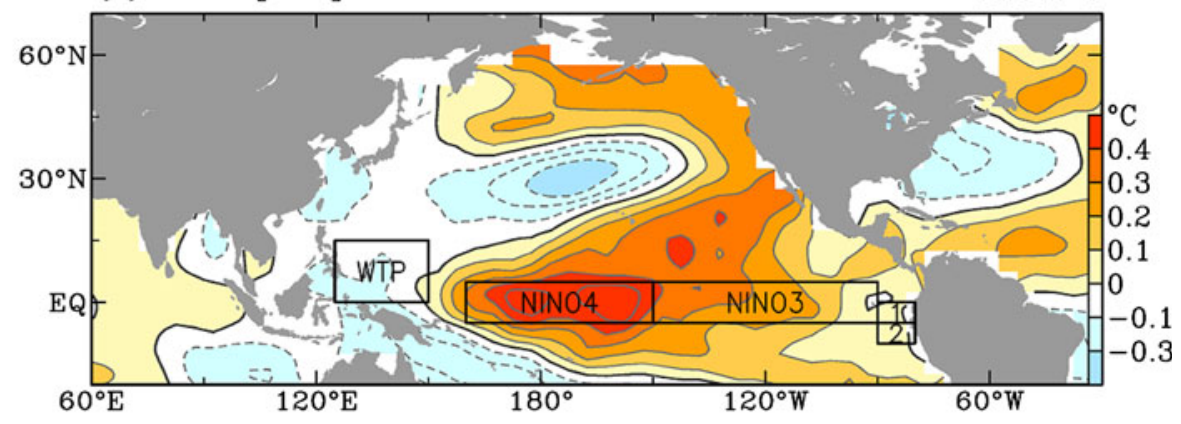

(d) REOF2[SST] $26.1 \%$

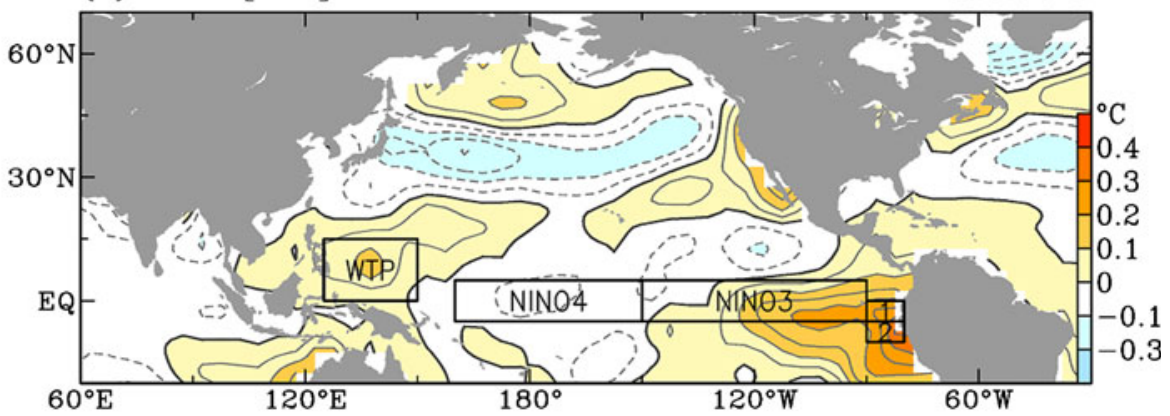

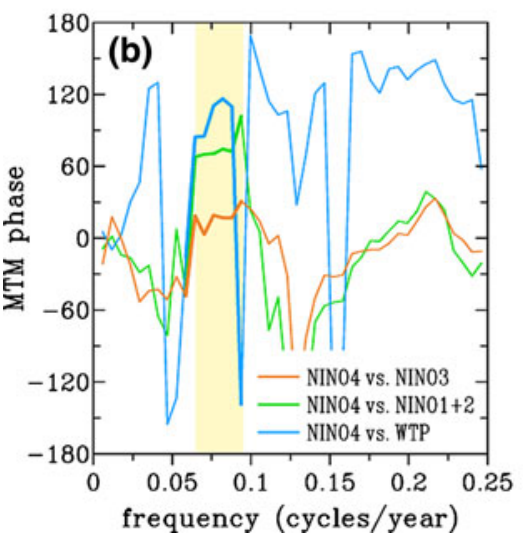

Fig. 1 a MTM power spectrum of the SST anomalies in the NINO4 (thick black curve), NINO3 (orange curve), NINO1 +2 (green curve), and WTP (blue curve) regions as outlined in (c). The 95\% confidence levels are indicated by dashed lines with the corresponding color. b MTM phase differences of SST between NINO4 and NINO3 (orange), NINO1 + 2 (green), and WTP (blue). The quasidecadal frequency is shaded in light yellow. Note that the phase lags of $180^{\circ}$ and $-180^{\circ}$ are the same. The phase difference at $0.07<f<0.1$ has the NINO4 SST leading other SST indices. c REOF 1 and d REOF 2 of the monthly Kaplan SST bandpassed by 10-15 year from 1948 to 2007 using the HW filter. Their eigencoefficients are shown in Fig. $2 \mathrm{c}$ and d. Contour interval is $0.1^{\circ} \mathrm{C}$ in (c) and $0.05^{\circ} \mathrm{C}$ in (d) 
Southern Oscillation Index (Moon and Lall 1996) and the NINO4 SST anomalies (WGJH) at this same frequency. Since the Great Salt Lake is a large closed basin in an arid region, its variations in elevation closely follow the precipitation variations but with a $90^{\circ}$ phase lag. Moreover, the quasi-decadal coherence between the Great Salt Lake elevation and the Pacific QDO manifests a quarter-phase relationship between the local precipitation regime and the Pacific QDO. In a recent study, Wang et al. (2009b) pointed out that precipitation variations in the central Intermountain West undergo a pronounced QDO, lagging the warm/cool phases of the Pacific QDO by 3 years which is equivalent to a quarter-phase of the 12 year cycle. Furthermore, the precipitation QDO in this region is linked to recurring circulation patterns over the Gulf of Alaska during the warm-cool and cool-warm transitions of the Pacific QDO. The regional climate variations noted by Wang et al. (2009b) suggest that a unique teleconnection likely develops in the transition phases of the Pacific QDO.

In light of the aforementioned findings, the present study examines the atmospheric circulation patterns associated with the evolution of the Pacific QDO. Emphasis is placed on investigating whether or not the tropical Pacific SST anomalies during the transition phases of the QDO induce systematic teleconnection patterns. A diagnostic approach is adopted with an ensemble of observational data and analysis schemes, which are introduced in Sect. 2. The large-scale SST and circulation patterns associated with the Pacific QDO life cycle, as well as the maintenance of any circulation anomalies, are discussed in Sect. 3. A summary with some concluding remarks are provided in Sect. 4.

\section{Data and methodology}

\subsection{Data}

Gridded datasets utilized here include the NCEP/NCAR Global Reanalyses (Kalnay et al. 1996), the version-2 Kaplan extended SST (Kaplan et al. 1998), the UK Meteorological Office Hadley Centre's observed mean sea level pressure version 2 (HadSLP2; Allan and Ansell 2006), the observed uninterpolated outgoing longwave radiation (OLR), the gauge-based Precipitation REConstruction over Land (PREC/ L; Chen et al. 2002) and the gauge and satellite-based PREC over Ocean (PREC/O; Xie et al. 2002), denoted hereafter as PREC. The Pacific QDO is often depicted using monthly SST data (Tourre et al. 2001; White and Tourre 2003; White and Liu 2008a, b). Thus, monthly data were used in this study. The analysis of the circulation, SST, and PREC covers a 60 year period from 1948 to 2007, while the spectral analysis of the SST covers 108 years from 1900 to 2007 in order to support the statistical significance of the QDO. Of note was that the
OLR data did not become available until 1975. All gridded datasets were obtained from the NOAA/OAR/ESRL Physical Sciences Division, Boulder, CO (http://www.cdc.noaa.gov).

\subsection{Diagnostic schemes for large-scale circulation}

Water vapor flux is an important form of the tropical circulation because the tropical atmosphere contains considerably higher moisture compared with the mid-/high latitude atmosphere. Chen (1985) converted the water vapor flux into a moisture flux streamfunction $\left(\psi_{Q}\right)$ and, a moisture flux potential $\left(\chi_{Q}\right)$-defined respectively as

$\psi_{Q}=\nabla^{-2}(\vec{k} \cdot \nabla \times Q)$

and

$\chi_{Q}=\nabla^{-2}(\nabla \cdot Q)$.

Since only the divergent moisture flux $\left(Q_{\mathrm{D}}\right)$ directly participates in the precipitation process, the water vapor budget equation can be expressed as

$\frac{\partial W}{\partial t}+\nabla^{2} \chi_{Q}=E-P$

where $W$ is precipitable water, $E$ is evaporation and $P$ is precipitation. Moisture transport mainly occurs in the moisture flux streamfunction $\psi_{Q}$. It will be shown later that the use of the moisture flux streamfunction, in particular, enhances the depiction of any circulation patterns associated with relatively weak tropical SST anomalies.

The diagnostics of possible source regions for the stationary wave anomalies were carried out by application of the Plumb flux, an extension of the Eliassen-Palm relation (Plumb 1985). The Plumb flux is defined on the log pressure coordinate system for the zonally averaged basic state, and may be expressed as

$F=p * \cos \phi\left\{\begin{array}{l}v^{\prime 2}-\frac{1}{2 \Omega a \sin 2 \phi} \frac{\partial\left(v^{\prime} \Phi^{\prime}\right)}{\partial \lambda} \\ -u^{\prime} v^{\prime}+\frac{1}{2 \Omega a \sin 2 \phi} \frac{\partial\left(u^{\prime} \Phi^{\prime}\right)}{\partial \lambda} \\ \frac{2 \Omega \sin \phi}{S}\left[v^{\prime} T^{\prime}-\frac{1}{2 \Omega a \sin 2 \phi} \frac{\partial\left(T^{\prime} \Phi^{\prime}\right)}{\partial \lambda}\right]\end{array}\right\}$

with

$S=\frac{\partial T}{\partial z}+\frac{g}{C_{P}}$

where $(u, v)$ are the horizontal wind vectors, $T$ is the temperature, $\Phi$ is the geopotential height, $\Omega$ is the earth's rotation rate, $p^{*}$ is pressure normalized to the $1,000 \mathrm{hPa}$ pressure level, $C_{P}$ is the specific heat at constant pressure, $a$ the radius of the Earth, and $\phi$ and $\lambda$ are latitude and longitude. Primes denote deviations from the zonal means and the caret signifies averaging over the area north of $10^{\circ} \mathrm{N}$. The Plumb flux diagnostic of stationary wave activity, presented here as a unit vector (unitless), is sensitive to the 
tropics-to-extratropics Rossby wave propagation from a tropical heating source and, thus, is useful in revealing remote forcings (Karoly et al. 1989; Barlow et al. 2001).

The atmospheric stationary waves in the tropics are driven by the divergent circulation which is maintained largely through diabatic heating (Krishnamurti 1971; Nigam et al. 1986). To illustrate the role of diabatic heating in the divergent circulation, we used the following velocity potential $(\chi)$ maintenance equation, which is derived from the combination of the thermodynamic and continuity equations (Chen and Yen 1991):

$\chi=\nabla^{-2}\left[\frac{\partial}{\partial p}\left(\begin{array}{c}\left.-\frac{1}{\sigma} V \cdot \nabla T\right) \\ \chi_{A}\end{array}\right]+\nabla^{-2}\left[\frac{\partial}{\partial p}\left(\frac{1}{\sigma} \frac{\dot{Q}}{\chi_{P}}\right)\right]\right.$,

where

$\sigma=-R T \frac{1}{p} \frac{d \ln \theta}{d \ln p}$.

Here $R$ is the gas constant for dry air, $\theta$ is the potential temperature, and $\dot{Q}$ is the diabatic heating obtained from the residual method of the thermodynamic equation. In the tropics, $\chi_{A}$ (velocity potential attributed to heat advection) is often neglected as $\chi_{H}$ (velocity potential attributable to diabatic heating) is usually dominant in the maintenance of the velocity potential due to strong diabatic/latent heating (Chen and Yen 1991).

To supplement the stationary wave activity revealed from Eq. 2 and the maintenance mechanism diagnosed from Eq. 3, we utilized a linear barotropic model developed by Branstator (1983) based on the spherical-surface vorticity equation:

$$
\begin{gathered}
\frac{\bar{u}_{Z}}{a \cos \varphi} \frac{\partial}{\partial \lambda}\left(\nabla^{2} \bar{\psi}_{E}\right)+\frac{1}{a^{2} \cos \varphi} \frac{\partial \bar{\psi}_{E}}{\partial \lambda} \frac{\partial}{\partial \varphi} \\
{\left[f-\frac{1}{a \cos \varphi} \frac{\partial}{\partial \varphi}\left(\bar{u}_{Z} \cos \varphi\right)\right]} \\
=F_{0}-\alpha \nabla^{2} \bar{\psi}_{E}+\gamma \nabla^{2} \bar{\psi}_{E},
\end{gathered}
$$

where $\bar{u}_{Z}$ is the annual-mean zonal wind, $\bar{\psi}_{E}$ the eddy streamfunction, and $f$ the Coriolis parameter. Coefficients of drag and diffusion are given as $\alpha\left(=1.57 \times 10^{-6} \mathrm{~s}^{-1}\right)$ and $\gamma\left(=2.34 \times 10^{16} \mathrm{~m}^{4} \mathrm{~s}^{-1}\right)$, respectively. The forcing $F_{0}$ is derived from vortex stretching. The vorticity (mass) source/sink is prescribed as a function decreasing linearly to a circular boundary with a center value of $3 \times 10^{-6} \mathrm{~s}^{-1}$, a modification from Branstator's (1983, 1985) elliptic boundary. This barotropic model is capable of resolving the midlatitude Rossby wave response to the equatorial Pacific SST anomalies and reproducing both the Pacific-North America (PNA) pattern (Branstator 1985) and the North Pacific ENSO short-wave train (Chen 2002). Since the analysis focuses on a time scale much longer than the seasonal cycle, the annual-mean climatological streamfunction at $500 \mathrm{hPa}$ was used as the background flow.

\section{Results and discussion}

\subsection{QDO in SST}

To determine a suitable frequency for the QDO, power spectrums of the monthly Kaplan SST anomalies in the NINO4, NINO3, NINO1 +2 , and the western tropical Pacific (WTP) regions (domain given in Fig. 1) from 1900 to 2007 were computed. The WTP region was included in the analysis because tropical convection is very sensitive to WTP SST variations, which more or less mirrors the ENSO activity (Chen 2002; DeWeaver and Nigam 2004). The spectral analysis utilizes the multi-taper method (MTM) that provides an optimally low-variance, highresolution spectral estimate and more accurately determines the noise component of the spectrum compared to the periodic (Fourier) method (Mann and Lees 1996; Mann and Park 1996). Figure 1a shows the robust estimate of SST signals obtained from the MTM spectral analysis. The pronounced interannual SST signals in the NINO4, NINO3, and NINO1 +2 regions are not the case for the WTP region, but the WTP SST shows much stronger low-frequency signals over the NINO4, NINO3, and NINO1 +2 regions. Nevertheless, the SST variations in all regions do reveal significant signals in the 10 15 year time scale with the largest spectrum in the NINO4 region. This observation is consistent with the Pacific SST variabilities presented in previous studies (e.g., Allan 2000).

Given the exceptionally strong quasi-decadal SST variability in the NINO4 region, we computed the phase differences of SST in the NINO4 region with other regions from the MTM spectral coherence analysis (Mann and Park 1996). Figure 1b shows that the SST anomalies in NINO4 and those in NINO3 and NINO1 +2 are generally in-phase. However, within the quasi-decadal frequency band, the SST phase difference between NINO4 and NINO1 +2 becomes $90^{\circ}$ phase shifted. Moreover, the phase difference between the NINO4 SST and the WTP SST is mostly opposite $\left(\sim 180^{\circ}\right)$ with the exception of the quasi-decadal frequency band; here a near $90^{\circ}$ phase shift exits and so, in the quasi-decadal time scale, the SST variation in NINO4 leads those in the NINO1 +2 and the WTP regions by a quarter-phase. Based on Fig. 1a and following WGJH, the 10-15 year frequency was adopted to represent the quasi-decadal time scale, and all variables were subsequently filtered by this frequency band. Filtering was performed using the Hamming-Windowed (HW) method (Hamming 1998) as this preserves the edges with minimum mean-square error and therefore is suitable for short-length time series (Iacobucci and Noullez 2005).

The Kaplan SST was then bandpassed by this 10 15 year frequency band and subsequently subjected to a 
rotated empirical orthogonal function (REOF) (Horel 1981) with the sum variance of the recombined leading modes exceeding $75 \%$. REOF1 of the SST (Fig. 1c; $51.2 \%$ of the total bandpassed variance) outlines an ENSO-like pattern with widespread central tropical Pacific warming centered at the NINO4 region, which is consistent with Allan (2000) and previous studies (cited earlier). REOF2 (Fig. 1d; $26.1 \%$ ) reveals weak cooling in the tropical central Pacific with noticeable warming in the NINO1 +2 and WTP regions. These features are consistent with their MTM phases (Fig. 1b) indicating that the NINO4 SST leads the NINO1 +2 SST and the WTP SST by a near $90^{\circ}$ phase. Meridionally stratified SST anomalies appear over the midlatitude North Pacific in both leading modes. The first two eigen-coefficients of SST are uniformly in-quadrature (Fig. 2c, d; shaded lines), suggesting that the REOF2 represents the rising/falling transitions of REOF1. Compared with the SST pattern shown in Tourre et al. 2001 (their Fig. 2) and White and Tourre (2003; their Fig. 2b), REOFs 1 and 2 represent the warm phase and the warm-cool transition phase of the Pacific QDO, respectively. The transition-phase SST pattern in Fig. 1d also resembles the SST structure forced by the 11-year solar cycle. The solarforced SST pattern is most apparent in the warm-cold transition process of the Pacific delayed action/recharge oscillator and thereby leads the warm-phase Pacific QDO by $90^{\circ}$ (White and Liu 2008a).

\subsection{Circulation structure}

Applying the REOF analysis on the bandpassed moisture flux streamfunction $\left(\psi_{Q}\right.$; with the global zonal mean removed for the depiction of stationary eddies), REOF 1 of $\psi_{Q}$ (Fig. $2 \mathrm{a} ; 48.4 \%$ of the bandpassed variance) reveals a circulation pattern dominated by the zonal wavenumber-1 component with a large cyclonic circulation in the midlatitude North Pacific. This broad cyclonic circulation reflects the deepened and eastward-shifted Aleutian low associated with the positive-phase Pacific Decadal Oscillation (Mantua et al. 1997) and the warm-phase North Pacific decadal variation (Trenberth and Hurrell 1994). Cyclonic flows over the WTP region depict the Southeast Asian-WTP monsoon trough that typically deepens during warm ENSO events (e.g., Wang and Chan 2002; Chen et al. 2006). The significant correlation between the eigencoefficients of $\psi_{Q}$ and SST (Fig. 2c) supports their close association, keeping in mind that the REOFs of $\psi_{Q}$ and SST were computed independently.

\section{(a) $\operatorname{REOF} 1\left[\psi_{\mathrm{a}}\right] \quad 48.4 \%$}

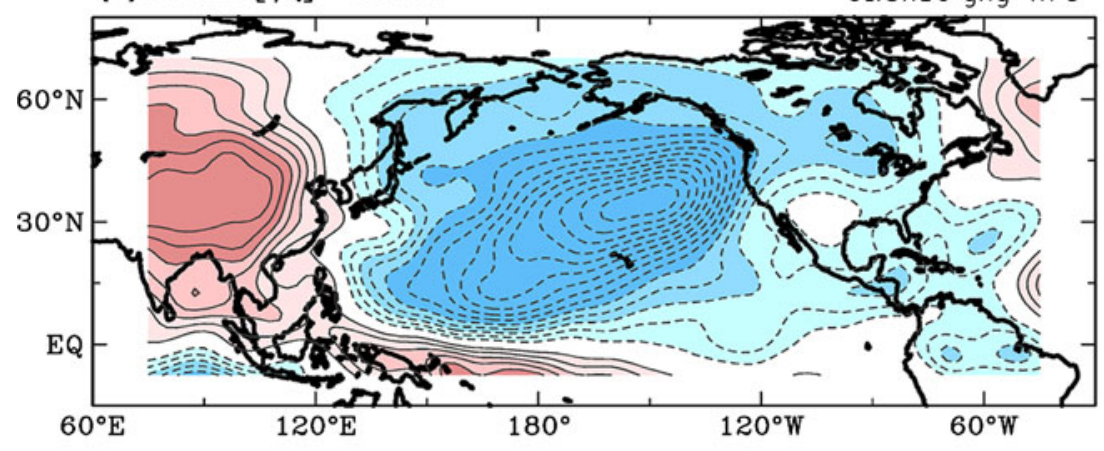

(b) $\operatorname{REOF} 2\left[\psi_{\mathrm{a}}\right] \quad 22.5 \%$

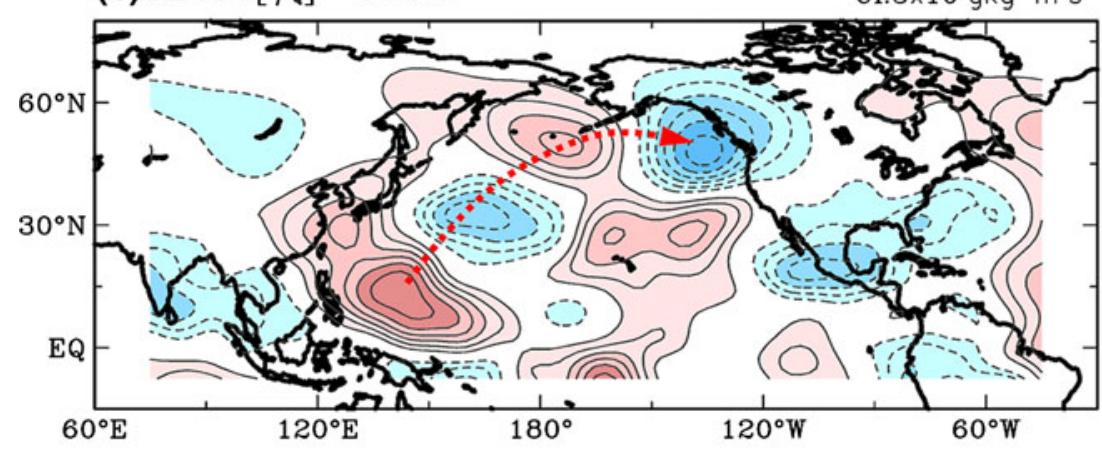

\section{(c) REOF1 $\left(\psi_{Q}, \mathrm{SST}\right)$}

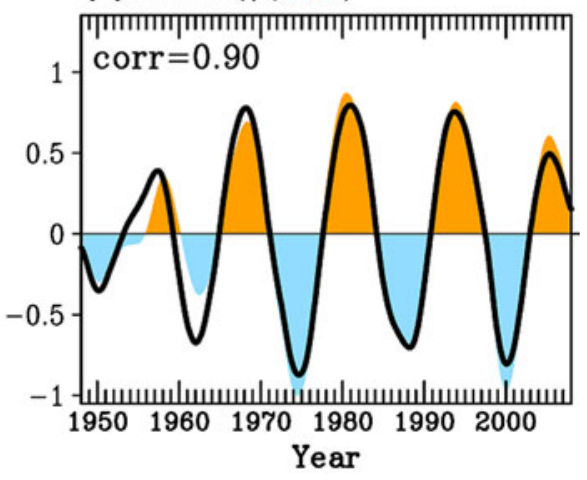

(d) $\operatorname{REOF2}\left(\psi_{a}, \mathrm{SST}\right)$

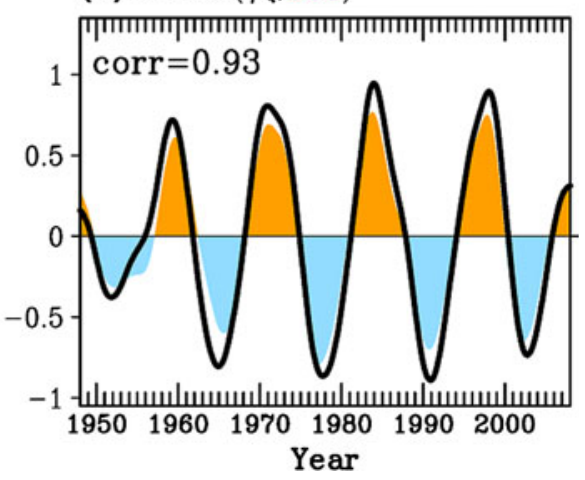

Fig. 2 a REOF 1 and b REOF 2 of the bandpassed moisture flux streamfunction $\left(\psi_{Q}\right)$. The normalized eigen-coefficients are shown in (c) and (d) as solid curves, with the eigen-coefficients of the bandpassed SST superimposed as shaded curves. Their correlation coefficients are given in the upper left. The short-wave train is indicated by a dashed arrow line in (b) 
In contrast to the dominant wavenumber-1 structure, REOF2 of $\psi_{Q}$ in Fig. $2 b$ (22.5\% of the bandpassed variance) reveals a pronounced short-wave train pattern. This short-wave train emanates from the WTP region and connects to the northwest US across the North Pacific. The highly correlated eigen-coefficients between $\psi_{Q}$ and SST (Fig. 2d) indicate that this short-wave train develops during the transition phases of the Pacific QDO (i.e. temporally in quadrature with REOF1). The circulation pattern of $\psi_{Q}$ in the central tropical Pacific is considerably weak, likely due to the relatively weak SST anomalies in this area (Fig. 1d). The cyclonic cell over the Gulf of Alaska, found to modulate the precipitation QDO in the central Intermountain West (WGJH), is embedded in the downstream region of the short-wave train. To validate the transition-phase pattern revealed from REOF 2, Fig. 3 shows the departure of the composite $\psi_{Q}$ during high-index and low-index years based on the REOF2 coefficient of the SST (Fig. 2d). The years with positive values exceeding the 0.8 standard deviation of the eigen-coefficient are 1958-1960, 19701973, 1983-1985, 1996-1999, and 2006. Years with significant negative values are 1952, 1965-1967, 1976-1979, 1990-1992, and 2002-2003. The data used for the composites were not filtered. Summer included June through August while winter was composed of December from the previous year through February. The anomalous patterns of $\psi_{Q}$ during winter (Fig. 3a) and summer (Fig. 3b) are very similar to each other and both reveal the short-wave train.

(a) $\Delta \psi_{\mathrm{Q}}$ (high-low index; DJF)

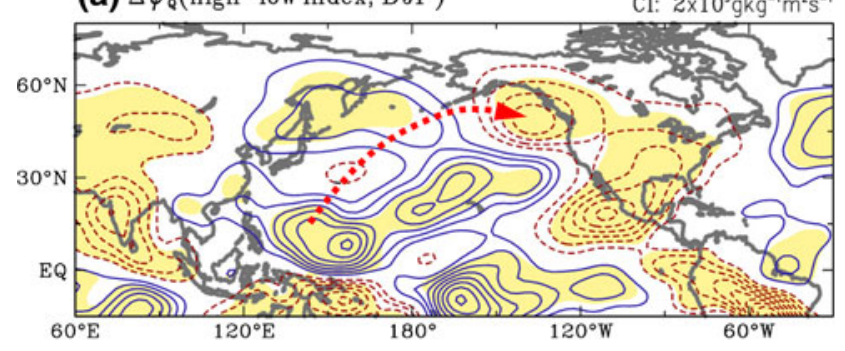

(b) $\Delta \psi_{\mathrm{Q}}($ high-low index; JJA)

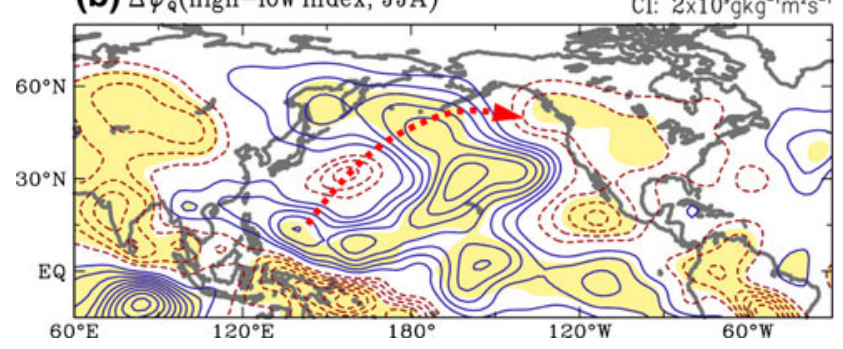

Fig. 3 Difference of the $\psi_{Q}$ composites between high-index and low-index years based on REOF2 of SST as in Fig. 2d during a December-February and b June-August using unfiltered data. Areas with $\psi_{Q}$ values above the $95 \%$ confidence level ( $t$ test) are shaded in light yellow. The dashed red arrow line indicates the short-wave train following Fig. 2b
The circulation magnitude appears to be weaker in summer than in winter, but the wave train pattern remains statistically significant at the $95 \%$ confidence level.

The tropospheric circulation associated with the warm-/ cool-phase Pacific QDO was examined by regressing the bandpassed eddy streamfunction $\left(\psi_{E}\right)$ upon the normalized eigen-coefficient of SST given in Fig. 2c. While the 200$\mathrm{hPa}$ streamfunction (Fig. 4a) depicts the classic PNA pattern (Horel and Wallace 1981), the 850-hPa streamfunction (Fig. 4b) shows the deepened and shifted Aleutian low similar to that revealed in $\psi_{Q}$ (Fig. 2a). Statistical significance of the regressed streamfunction patterns are provided separately at http://cliserv.jql.usu.edu/paper/CD/Si_test.pdf . The tropical circulation patterns at both levels together with the SLP pattern are dominated by a globally zonal wavenumber-1 structure alternating between the eastern Pacific and the Asian-Australian monsoon region. These features bear a resemblance to the circulation anomalies associated with the positive-phase Pacific Decadal Oscillation (Zhang et al. 1997; Enfield and Mestas-Nuñez 1999; Chen et al. 2008).

When regressed upon REOF2 of the SST, the 200-hPa streamfunction (Fig. 4c) reveals wave-form circulation anomalies across the midlatitude North Pacific connected to the cyclonic cell of $\psi_{Q}$ over the Gulf of Alaska (cf. Fig. 2b). WGJH noted that the circulation dipole west of North America, consisting of a cyclonic cell in the Gulf of Alaska and an elongated anticyclonic cell to the west of the California coast, strengthens the jet stream and, consequently enhances the synoptic transient activity across the central Intermountain West. At $850 \mathrm{hPa}$, the streamfunction pattern (Fig. 4d) basically resembles the $\psi_{Q}$ shortwave train but shows weaker anomalies in the tropics. The SLP anomalies are noticeably weaker at lower latitudes and do not show any meaningful patterns throughout the tropics; this demonstrates the strengthening effect of the moisture flux on the tropical circulation anomalies, especially when the tropical SST forcing is weak. According to Fig. 4c and d, the short-wave train is barotropic in the midlatitudes and becomes vertically reversed (or baroclinic) in the upstream tropics, suggesting the occurrence of latent heating through tropical cumulus convection. Such a short-wave train structure and the inferred forcing source are consistent with previous findings of North Pacific wave trains emanating from East Asia and the WTP region during winter (Chen 2002; DeWeaver and Nigam 2004) and summer (Lau and Weng 2002; Barlow et al. 2001).

To diagnose the possible forcing source region of this short-wave train, the stationary wave flux activity $(F)$ at $200 \mathrm{hPa}$ from Eq. 2 was regressed upon the normalized eigen-coefficients of the SST. During the warm/cool phase of the Pacific QDO, as shown in Fig. 4a, the flux of stationary wave activity at $200 \mathrm{hPa}$ emanates from two main 
[ Warm phase ]

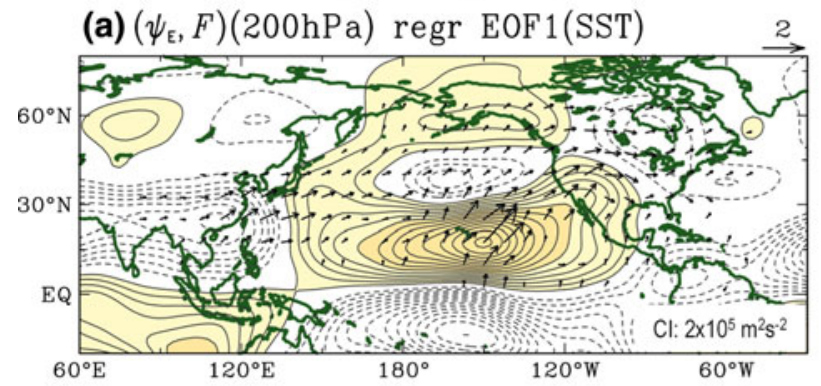

(b) $\left[\psi_{\mathrm{E}}(850 \mathrm{hPa}), \mathrm{SLP}\right]$ regr EOF1(SST)

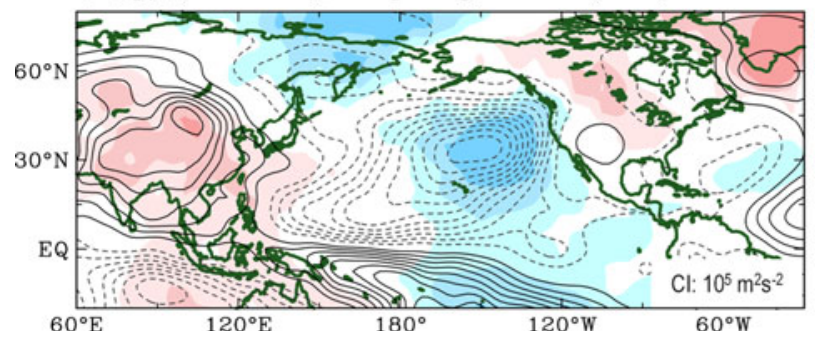

Fig. 4 Distributions of regression coefficients of the bandpassed a 200 -hPa eddy streamfunction $\left(\psi_{E}\right)$ and stationary wave activity flux ( $F$; vectors) and b 850 -hPa eddy streamfunction ( $\psi_{E}$; contours) and sea level pressure (HadSLP2; shadings) with REOF1 of SST in Fig. 2c. For plots $\mathbf{c}$ and $\mathbf{d}$, same as (a) and (b) but regressed upon REOF2 of SST in Fig. 2d. Contour intervals and vector length are
[ Warm-to-cool transition phase]

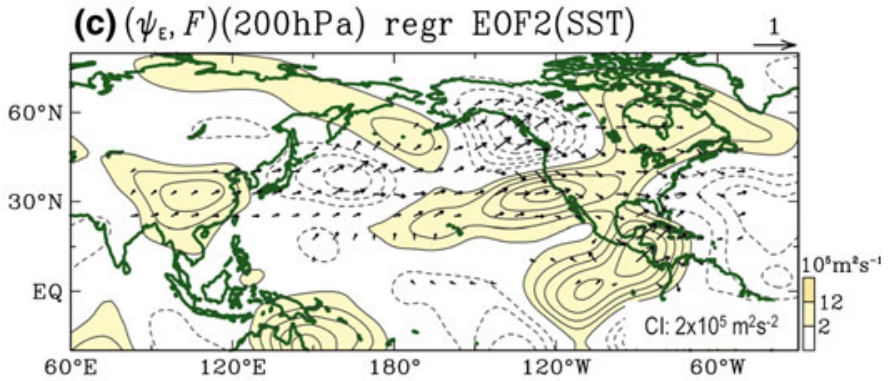

(d) $\left[\psi_{\mathrm{E}}(850 \mathrm{hPa}), \mathrm{SLP}\right]$ regr EOF2 $(\mathrm{SST})$

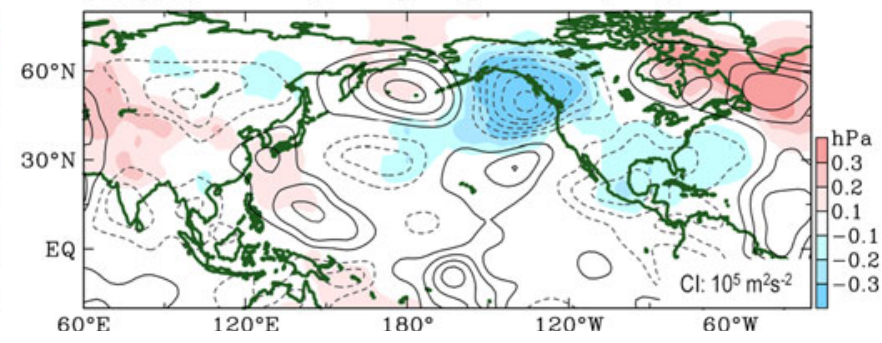

given in the lower right and upper right, respectively. The short-wave train is indicated in (c) and (d). Only vector and sea level pressure signals surpassing the $95 \%$ significance level were plotted. The significance test for the eddy streamfunction is presented separately (ref. text)

$\psi_{Q}$, and SST in a global domain $\left[0^{\circ}-360^{\circ}, 20^{\circ} \mathrm{S}-60^{\circ} \mathrm{N}\right]$ were bandpassed with 10-15 years using the HW filter and displayed in Fig. 5a. The evolution of the variances in $\psi(200 \mathrm{hPa}), \psi_{Q}$, and SST are consistent with each other and, all of them correspond well with the Pacific QDO (yellow-shaded curves). Such observations suggest that the magnitude of the zonal wavenumber- 1 component of the circulation anomalies closely follows that of the SST anomalies. While the maximum wavenumber- 1 variances occur during both the warm and cool phases of the Pacific QDO, the minimum variances take place in both the rising and falling transitions of the Pacific QDO. These results support the observation by White and Tourre (2003) that SST and SLP covarying with ENSO at different time scales are characterized by a dominant zonal wavenumber- 1 structure-as observed in Figs. 1d and 4b. In the meantime, the variances of $\psi(200 \mathrm{hPa}), \psi_{Q}$, and SST in the short-wave regime, with both wavenumber-1 and zonal mean components removed, also fluctuate coherently (Fig. 5b). In this case, the peaks (troughs) of the shortwave variances systematically occur in the falling (rising) transitions of the Pacific QDO when the wavenumber-1 variances are minimal. The results of Fig. 5 illustrate a magnitude alternation between the wavenumber- 1 structure and the shorter-wave structure in SST and circulation following the Pacific QDO evolution. 


\subsection{Circulation maintenance}

It is generally accepted that the ENSO/ENSO-like teleconnection patterns are excited from tropical heating influenced by the SST and/or convective anomalies (Philander 1990; Clarke 2008). Because the atmospheric divergent circulation directly responds to such heating (e.g., Krishnamurti 1971), examining the thermodynamic maintenance of the divergent circulation may help in the verification of the circulation patterns associated with transition phases of the Pacific QDO. The ENSO-like circulation structure and the dynamics coupled to the warm-/ cool-phase Pacific QDO have been thoroughly discussed
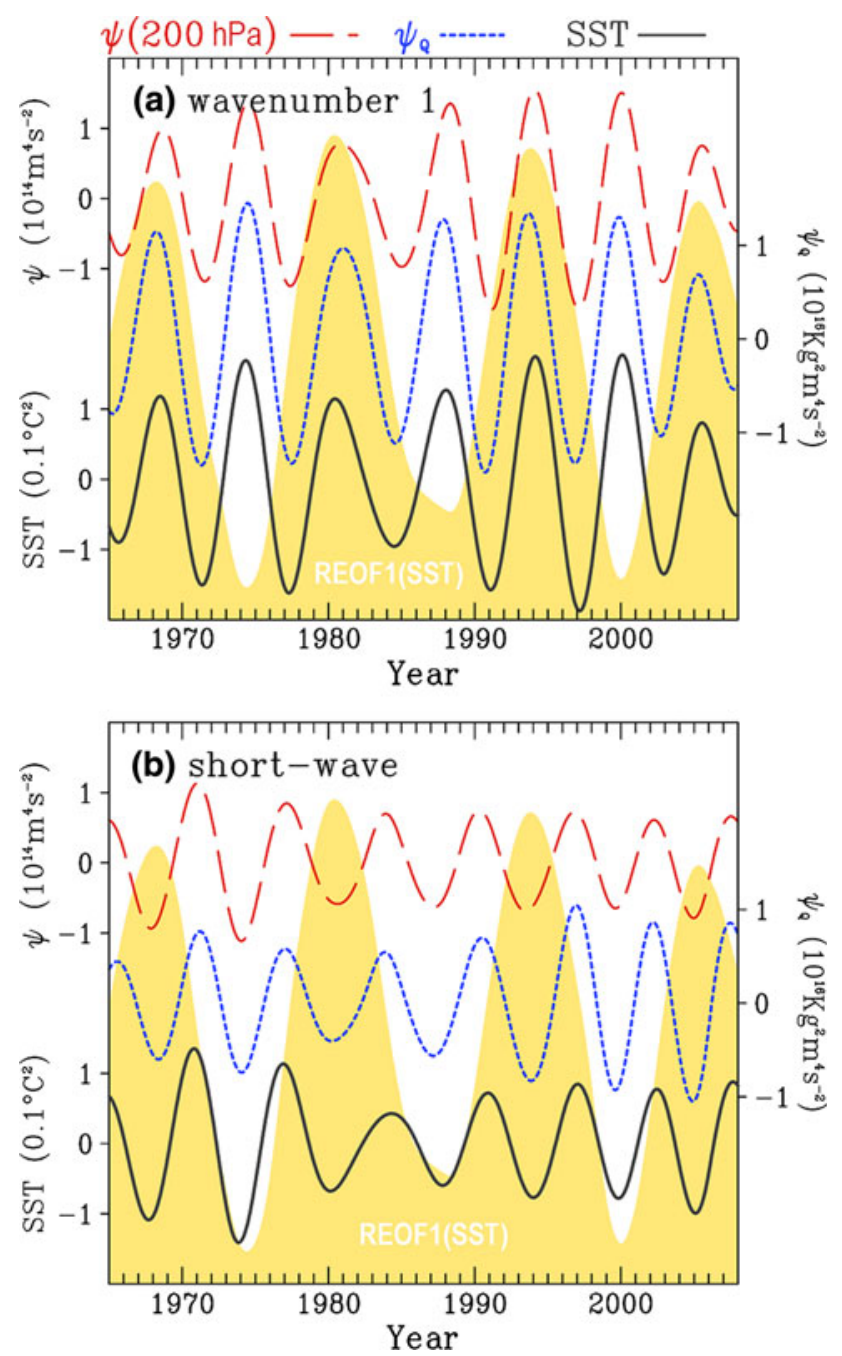

Fig. 5 Spatial variances within the global domain $\left(0^{\circ}-360^{\circ}, 20^{\circ} \mathrm{S}-\right.$ $60^{\circ} \mathrm{N}$ ) of the a zonal wavenumber- 1 and $\mathbf{b}$ residual-wave components of the bandpassed 200-hPa streamfunction ( $\psi$; red long-dashed line), moisture flux streamfunction $\left(\psi_{Q}\right.$; blue dashed line) and SST (gray solid line). For comparison, the normalized REOF1 coefficient of SST, adopted from Fig. 2c, is superimposed as shaded curves in yellow (e.g., Chen et al. 2008). For brevity, the following analysis only focuses on the transition phases of the Pacific QDO.

Following Fig. 4c and d, the bandpassed velocity potential $(\chi)$ was regressed upon the normalized REOF2 coefficient of SST given in Fig. 2d and is shown in Fig. 6. Wave-form patterns of $\chi$ emerge at both the $200 \mathrm{hPa}$ (Fig. 6a) and $850 \mathrm{hPa}$ (Fig. 6b) pressure levels. In the tropics, $\chi(200 \mathrm{hPa})$ reveals distinct divergence centers over the Maritime Continent, the central-eastern Pacific $\left(140^{\circ} \mathrm{W}\right)$, and the western Atlantic $\left(\sim 60^{\circ} \mathrm{W}\right)$, together with marked convergence centers over the central-western Pacific $\left(\sim 170^{\circ} \mathrm{E}\right)$ and the eastern North Pacific $\left(\sim 120^{\circ} \mathrm{W}\right)$. The trans-Pacific wave train is readily visible over the midlatitude North Pacific and appears to be horizontal in quadrature from the $\psi$ and $\psi_{Q}$ short-wave trains. Each of the divergence and convergence centers at $200 \mathrm{hPa}$ is accompanied by opposite-phase anomalies in $\chi(850 \mathrm{hPa})$, indicating a vertically coupled mass-flux circulation. Statistical significance of the regressed $\chi(200 \mathrm{hPa})$ and $\chi(850 \mathrm{hPa})$ are presented separately at http://cliserv.jql.usu.edu/paper/CD/ Chi_test.pdf.

Velocity potential is mainly driven by diabatic heating near the tropics (e.g., Chen and Yen 1991) in which the OLR portrays well the radiative emission of cloud tops in areas of deep convection. The regression patterns of the OLR and precipitation are superimposed in Fig. 6a and b, respectively. The patterns of the OLR and precipitation are phase coincident with each other and with the divergent circulation. Negative OLR and positive precipitation (i.e. enhanced convection) are co-located with upper-level divergence and low-level convergence, while positive OLR and negative precipitation (i.e. suppressed convection) are phase-coincident with upper-level convergence and lowlevel divergence. In the midlatitude North Pacific, the spatial phases of the OLR and precipitation are also consistent with the short-wave train. In the western US, the low-level convergence and upper-level divergence are colocated with the enhanced precipitation (Fig. 6b). Such a finding further supports the quadrature phase association between the precipitation QDO in the Intermountain West and the Pacific QDO as outlined in WGJH. Because of the shorter overlap between the OLR data and the NCEP/ NCAR Reanalysis data, statistical significance was not calculated, therefore the results should be considered suggestive rather than conclusive.

To illustrate the role of diabatic heating in the divergent circulation, the velocity potential maintenance equation for stationary waves in Eq. 3 was examined. At the $200 \mathrm{hPa}$ level (Fig. 6c), the regression patterns of diabatic heatinginduced velocity potential $\left(\chi_{H}\right)$ and diabatic heating $(\dot{Q})$ resemble $\chi(200 \mathrm{hPa})$ and the OLR shown in Fig. 6a. The resemblance is strong not only over the tropical Pacific but also over the Gulf of Alaska and the Western US. Spatial 

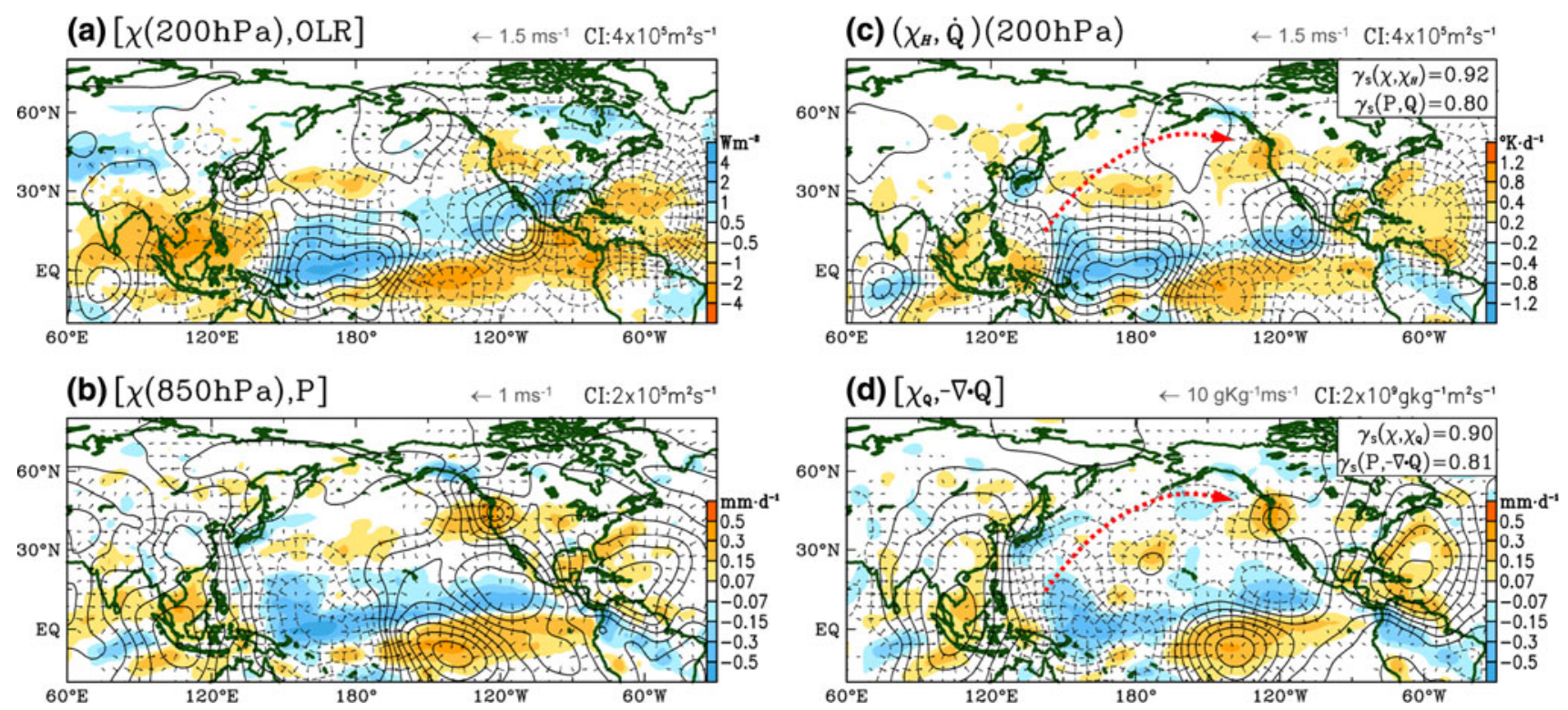

Fig. 6 Same as Fig. 4 but for regression coefficients of bandpassed a 200-hPa and b $850-\mathrm{hPa}$ velocity potential $(\chi)$, c 200-hPa velocity potential derived from Eq. $3,\left(\chi_{H}\right)$ and $\mathbf{d}$ moisture flux potential $\left(\chi_{Q}\right)$ with the normalized REOF2 coefficient of SST, superimposed with regressions coefficients of the OLR, precipitation (PREC), diabatic

heating $(\dot{Q})$, and convergence of water vapor flux $(-\nabla \cdot Q)$ (shadings), respectively. The divergent wind and water vapor flux vectors are derived from the regression coefficients. The short wave train is indicated by red dashed arrow lines in (c) and (d)

correlation coefficients between $(\dot{Q})$ and OLR and between $\chi(200 \mathrm{hPa})$ and $\chi_{H}(200 \mathrm{hPa})$ are 0.8 and 0.92 , respectively, supporting their near-balanced state in the maintenance relationship of Eq. 3. Compared to $\chi(200 \mathrm{hPa})$, the amplitude of $\chi_{H}(200 \mathrm{hPa})$ is smaller in the middle and high latitudes where the magnitude of heat transport $\left[\chi_{A}(200 \mathrm{hPa})\right]$ increases (not shown). It was found that $\chi_{A}(200 \mathrm{hPa})$ accounts for $12 \%$ of the variance of $\chi(200 \mathrm{hPa})$ north of $35^{\circ} \mathrm{N}$ and less than $5 \%$ of the variance south of $35^{\circ} \mathrm{N}$. Over the Western US, the increased contribution of $\chi_{A}(200 \mathrm{hPa})$ to $\chi(200 \mathrm{hPa})$ reflects the enhanced westerly jet across $45^{\circ} \mathrm{N}$ (cf. Fig. 4c).

Low-level velocity potential was compared with the moisture flux potential $\left(\chi_{Q}\right)$ derived from Eq. 1. The regression pattern of $\chi_{Q}$ (Fig. 6d) is very similar to $\chi(850 \mathrm{hPa})$ (Fig. 6b) with a spatial correlation coefficient of 0.9 . The regressed pattern of water vapor flux convergence $\left(-\nabla \cdot Q_{\mathrm{D}}\right)$ also resembles that of precipitation (Fig. 6b) and is supported by a spatial correlation coefficient of 0.81 . The remaining difference between precipitation (Fig. 6b) and the water vapor flux convergence $\left(-\nabla \cdot Q_{\mathrm{D}} ;\right.$ Fig. $\left.6 \mathrm{~d}\right)$ is theoretically balanced by evaporation in the context of the global hydrological cycle as shown in Ruane and Roads (2008). Noteworthy is that the shortwave train appears more clearly in $\chi_{Q}$ than $\chi(850 \mathrm{hPa})$. Furthermore, the opposite phases between $\chi_{H}(200 \mathrm{hPa})$ and $\chi_{Q}$ reflect the moist teleconnection mechanism (Su and Neelin 2002; Neelin 2007) in which the moist stability equilibrium of the tropical teleconnection is

maintained by horizontal motions (with moisture) converging at low levels, rising and diverging aloft (with heating). Such a mechanism is particularly important given the small horizontal pressure gradients that exist in the tropics and is well depicted in the moisture flux streamfunction (cf. Fig. 2b) and the moisture flux potential (cf. Fig. 6d).

\subsection{Possible forcing}

Trans-Pacific wave trains excited from the Southeast AsiaWTP region are not a new discovery. Numerous studies (e.g., Branstator 1985; Lau and Weng 2002; Jiang and Lau 2008) suggest that diabatic and/or sensible heat sources in that area can induce Rossby wave trains toward the midlatitudes. For instance, during El Niño (La Niña) conditions, trains of stationary Rossby waves spanning the North Pacific can be induced by anomalous cooling (warming) in the Philippine Sea $\left(\sim 140^{\circ} \mathrm{E}\right)$ either directly through a Rossby-wave response (DeWeaver and Nigam 2004) or indirectly through a local Hadley circulation (Chen 2002). However, as shown in the panels of Fig. 6, the major heating and precipitation/OLR anomalies near the South China Sea $\left(\sim 110^{\circ} \mathrm{E}\right)$ and the cooling over the NINO4 region appear to deviate from those typically found in the El Niño and La Niña episodes. To examine if these anomalous heating distributions can indeed induce a Rossby-wave response, as was noted earlier, as well as to verify the Plumb flux diagnostic given in Fig. 4, the 
barotropic diagnostic model described by Eq. 4 was applied and tested.

Based on the distribution of the precipitation and velocity potential anomalies in the tropics (Fig. 6), two mass sources were placed near the South China Sea $\left(115^{\circ} \mathrm{E}, 10^{\circ} \mathrm{N}\right)$ and the eastern equatorial Pacific $\left(140^{\circ} \mathrm{W}\right.$, EQ) and a mass sink was set up in the central equatorial Pacific $\left(165^{\circ} \mathrm{E}, 5^{\circ} \mathrm{N}\right)$, as illustrated in Fig. 7. When forced only from the South China Sea (Fig. 7a), the steady solution reveals a train of waves emanating from the mass source toward the Gulf of Alaska, first directed poleward and then eastward. The wave path coincides with the subtropical jet known to direct the wave-activity flux (Takaya and Nakamura 2001; Barlow et al. 2001; Jiang and Lau 2008). The cyclonic cell to the west and the anticyclonic cell to the east of the vorticity source delineate a Rossby wave response to diabatic heating typical in the tropical region, which is described in Gill (1980). Meanwhile, the mass sink in the central equatorial Pacific, corresponding to anomalous cooling there (cf. Fig. 6c), enhances the anticyclone in the WTP as well as the shortwave train structure (Fig. 7b). An additional mass source set up in the eastern equatorial Pacific (Fig. 7c) further
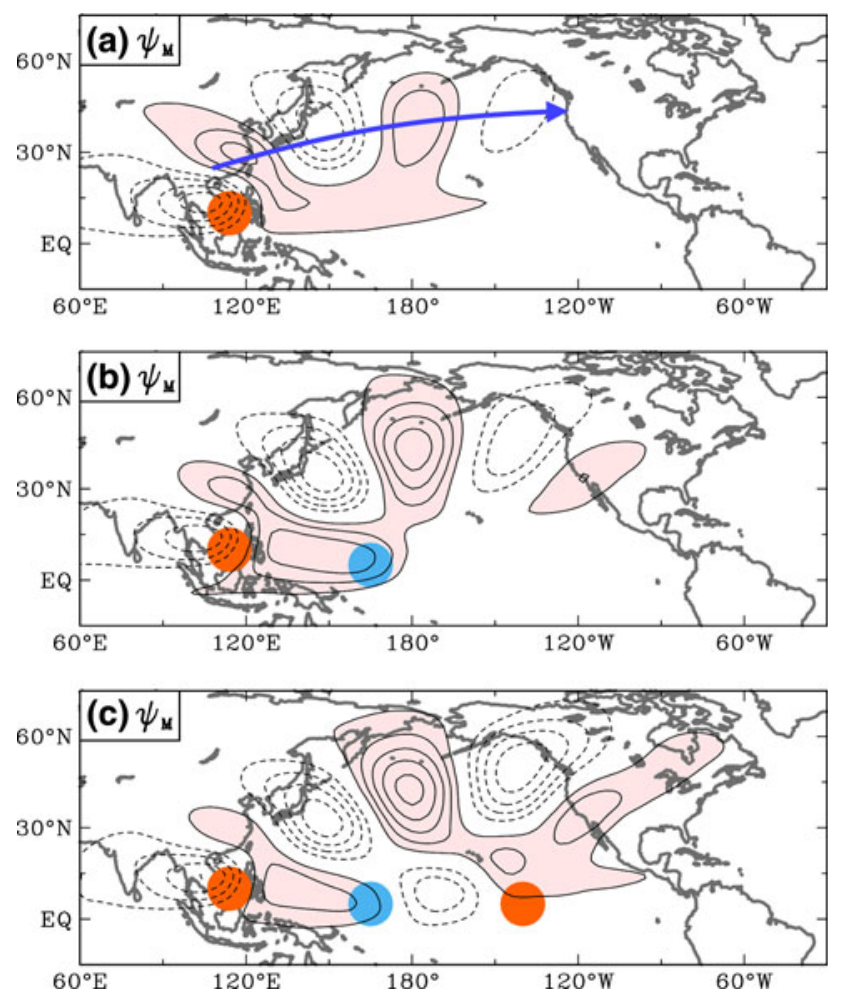

Fig. 7 a-c The eddy streamfunction response to three combinations of mass sources/sink (ref. text). The locations of the mass sources and sink are indicated by red and blue dots, respectively. The annualmean $500-\mathrm{hPa}$ westerly jet core, following the $20 \mathrm{~m} \mathrm{~s}^{-1}$ isotach, is indicated by the blue arrow line in (a). The contour interval is $10^{7} \mathrm{~m}^{2} \mathrm{~s}^{-1}$ enhances the short-wave train in the downstream region. According to the Gill model, this eastern equatorial Pacific forcing forms an extensive cyclonic circulation to its west and subsequently weakens the WTP anticyclone as was previously observed in Fig. $7 \mathrm{~b}$.

These linear model solutions are a crude representation of the atmospheric response to tropical forcings, since a reasonable choice for a forcing magnitude remains uncertain and the background large-scale flows may change from year to year. Nevertheless, the resemblance between the "simulated" and observed circulation patterns (cf. Figs. 7c, $4 d$ ), together with the established knowledge of transPacific wave trains outlined in previous studies, indicate that this short-wave train is dynamically possible and, that it emerges in close association with the transition-phase SST pattern of the Pacific QDO. How the precipitation and heating anomalies respond to the SST pattern remain openended questions and will require further analyses.

We do however note that the forcing source in the eastern equatorial Pacific which acts to enhance the cyclonic cell over the Gulf of Alaska is not apparent in the Plumb flux (Fig. 4c); this may be a result of the oceanatmosphere coupled feedback proposed by van Loon et al. (2007), who suggested that weak, cold ENSO-like SST anomalies in the eastern Pacific associated with the solar cycle can strengthen the trade winds and increase precipitation in the South Pacific convergence zone. The convergence zone subsequently generates local Hadley-like circulations with an ascending branch over the eastern tropical Pacific and a descending branch over the eastern subtropical Pacific which, in turn, induces a secondary circulation with an ascending branch at higher latitudes $\left(40^{\circ}-50^{\circ} \mathrm{N}\right)$. Similar features are also discernable in Fig. $6 \mathrm{a}$ and b: across the eastern Pacific near $130^{\circ} \mathrm{W}$, the strong low-level convergence between $20^{\circ} \mathrm{S}$-EQ is paired with a divergence center between $10^{\circ} \mathrm{N}-30^{\circ} \mathrm{N}$ south of a local convergence center over the Western US $\left(\sim 45^{\circ} \mathrm{N}\right)$. This divergent circulation portrays a meridional secondary circulation with an ascending branch over the Western US and a descending branch in the subtropical eastern North Pacific. As pointed out in van Loon et al. (2007) and previously by Karoly et al. (1989), a secondary circulation such as this may enhance, through geostrophic adjustment, the downstream cyclonic cell of the short-wave train.

\section{Summary and conclusions}

The Pacific QDO features a well-defined lifecycle with distinctive phases reflected in the SST and SLP patterns; it forms not only ENSO-like patterns in the warm/cool phase, but also recurrent patterns during the transition phases (Tourre et al. 2001; White and Tourre 2003). Here, we 
examined the impact of the transition-phase SST pattern of the Pacific QDO on the atmospheric teleconnection. Using various diagnostic methods and applying existing theories, this study reports on a teleconnectional shortwave train that develops during the transition phases of the Pacific QDO. Substantial agreement between the anomalous patterns of the OLR, precipitation, diabatic heating, and the moisture flux convergence in the quasidecadal time scale were demonstrated, suggesting that this short-wave train is indeed thermodynamically maintained. It appears that the short-wave train is mainly induced by heating anomalies in the WTP region, but additional modulations from forcing sources in the central and eastern equatorial Pacific are also present. Previous findings regarding similar wave trains across the North Pacific also lend some support to this particular shortwave train. Moreover, the absence of widespread ENSOlike tropical Pacific SST anomalies during the transition phases of the Pacific QDO diminishes the zonal wavenumber-1 component of the circulation patterns, thereby revealing short-wave circulation patterns in response to heating anomalies scattered across Southeast Asia and the tropical Pacific.

Due to limited availability of global wind observations, studies that focus on decadal or longer time scales of the Pacific climate variability often utilize long-term SLP (such as the decade-long HadSLP2) instead of observations of tropospheric winds. However, the surface pressure fields are generally incapable of depicting the tropical circulation. A well-known deficiency of SLP, it again becomes apparent in Fig. 3d in which the short-wave train south of $30^{\circ} \mathrm{N}$ is only discernable in the streamfunction fields while the SLP anomalies are too weak to make an evaluation. Additionally, the use of the water vapor flux dramatically enhances the depiction of any circulation anomalies in the moist tropics, as was demonstrated by contrasting the short-wave train structure between the moisture flux streamfunction (Fig. 2b) and the streamfunction (Fig. 3d); this implies that moisture weighting is important to lowertropospheric circulations in the tropics. Readers are referred to a review by Neelin (2007) for the role of moisture on the tropical teleconnection.

The direct impacts of ENSO, the Pacific QDO, and other interdecadal variation modes on the global hydrological cycle have been extensively studied (e.g., Dettinger et al. 2000). In addition, a "non-linear coupling" of precipitation variations around the globe with those Pacific climate modes have been observed in part of the tropical Pacific (Khan et al. 2006), East Asia (Li 1998), Eurasia (Ye 2001), and the Western US (WGJH). The precipitation variations in these regions exhibit similar spectrums with the SST variations in the central tropical Pacific, but their phases are consistently different (or shifted). It is likely that the transition phase teleconnection of the Pacific QDO may play a role in such spectral coherence and phase difference, as it does in forming the quasi-decadal cycles of the Intermountain precipitation in the US which, as reported in WGJH, consistently lags the Pacific QDO by a quarterphase.

Acknowledgment We thank A. Iacobucci at University of ParisDauphine for sharing with the HW filter package, P. Xie and M. Chen for providing the PREC/O/L data, T.-C. Chen for the barotropic model and M. Booth for editorial assistance. Insightful comments offered by two anomalous reviewers are appreciated. This study was supported by the USDA-CSREES funded Drought Management, Utah Project, and the Utah Agricultural Experiment Station, Utah State University, and approved as journal paper number 8107.

Open Access This article is distributed under the terms of the Creative Commons Attribution Noncommercial License which permits any noncommercial use, distribution, and reproduction in any medium, provided the original author(s) and source are credited.

\section{References}

Allan RJ (2000) ENSO and climatic variability in the last 150 years. In: Diaz HF, Markgraf V (eds) El Niño and the Southern Oscillation: multiscale variability, global and regional impacts. Cambridge University Press, Cambridge, UK, pp 3-56

Allan RJ, Ansell TJ (2006) A new globally-complete monthly historical gridded mean sea level pressure data set (HadSLP2): 1850-2004. J Clim 19:5816-5842

Barlow M, Nigam S, Berbery EH (2001) ENSO, Pacific Decadal Variability, and US summertime precipitation, drought, and stream Flow. J Clim 14:2105-2128

Branstator G (1983) Horizontal energy propagation in a barotropic atmosphere with meridional and zonal Structure. J Atmos Sci 40:1689-1708

Branstator G (1985) Analysis of general circulation model sea-surface temperature anomaly simulations using a linear model. Part I: Forced solutions. J Atmos Sci 42:2225-2241

Chen TC (1985) Global water vapor flux and maintenance during FGGE. Mon Weather Rev 113:1801-1819

Chen TC (2002) A North Pacific short-wave train during the extreme phases of ENSO. J Clim 15:2359-2376

Chen TC, Yen MC (1991) A study for the diabatic heating associated with the planetary scale Madden-Julian Oscillation. J Geophys Res 96:163-177

Chen M, Xie P, Janowiak JE, Arkin PA (2002) Global land precipitation: a 50 -yr monthly analysis based on gauge observations. J Hydrometeorol 3:249-266

Chen TC, Wang SY, Yen MC (2006) Interannual variation of the tropical cyclone activity over the western North Pacific. J Clim 19:5709-5720

Chen J, Del Genio AD, Carlson BE, Bosilovich MG (2008) The spatiotemporal structure of twentieth-century climate variations in observations and reanalyses. Part II: Pacific pan-decadal variability. J Clim 21:2634-2650

Clarke AJ (2008) An introduction to the dynamics of El Nino \& the Southern Oscillation. Academic Press, Elsevier, New York, p 301

Dettinger MD, Cayan DR, McCabe GJ, Marengo JA (2000) Multiscale streamflow variability associated with El Niño/ 
Southern Oscillation. In: Diaz HF, Markgraf V (eds) El Niño and the Southern Oscillation: multiscale variability, global and regional impacts. Cambridge University Press, Cambridge, UK, pp 113-148

DeWeaver E, Nigam S (2004) On the forcing of ENSO teleconnections by anomalous heating and cooling. J Clim 17:3225-3235

Enfield DB, Mestas-Nuñez AM (1999) Multiscale variabilities in global sea surface temperatures and their relationships with tropospheric climate patterns. J Clim 12:2719-2733

Fyfe JC, Saenko OA (2007) Anthropogenic speed-up of oceanic planetary waves. Geophys Res Lett 34:L10706. doi:10.1029/ 2007GL029859

Gill AE (1980) Some simple solutions for heat induced tropical circulation. Q J R Meteorol Soc 106:447-462

Hamming RW (1998) Digital Filters, 3rd edn. Dover Publications, New York

Horel JD (1981) A rotated principal component analysis of the interannual variability of the Northern Hemisphere $500 \mathrm{mb}$ height field. Mon Weather Rev 109:2080-2092

Horel JD, Wallace JM (1981) Planetary-scale atmospheric phenomena associated with the Southern Oscillation. Mon Weather Rev 109:813-829

Iacobucci A, Noullez A (2005) A frequency selective filter for shortlength time series. Comput Econ 25:75-102

Jiang X, Lau NC (2008) Intraseasonal teleconnection between North American and western North Pacific monsoons with 20-day time scale. J Clim 21:2664-2679

Jin FF (1997) An equatorial ocean recharge paradigm for ENSO. Part I. Conceptual model. J Atmos Sci 54:811-829

Kalnay E et al (1996) The NCEP/NCAR 40-year reanalysis project. Bull Amer Meteor Soc 77:437-470

Kaplan A, Cane M, Kushnir Y, Clement A, Blumenthal M, Rajagopalan B (1998) Analyses of global sea surface temperature 1856-1991. J Geophys Res 103:567-589

Karoly D, Plumb RA, Ting M (1989) Examples of the horizontal propagation of quasi-stationary waves. J Atmos Sci 46:28022811

Khan S, Ganguly AR, Bandyopadhyay S, Saigal S, Erickson DJ III, Protopopescu V, Ostrouchov G (2006) Nonlinear statistics reveals stronger ties between ENSO and the tropical hydrological cycle. Geophys Res Lett 33:L24402

Krishnamurti TN (1971) Tropical east-west circulations during the Northern Summer. J Atmos Sci 28:1342-1347

Lall U, Mann M (1995) The Great Salt Lake: a barometer of lowfrequency climatic variability. Water Resour Res 31:2503-2515

Lau KM, Weng H (2002) Recurrent teleconnection patterns linking summertime precipitation variability over East Asia and North America. J Meteor Soc Japan 80:1309-1324

Li C (1998) The quasi-decadal oscillation of air-sea system in the northwestern Pacific region. Adv Atmos Sci 15:31-40

Lohmann K, Latif M (2005) Tropical Pacific decadal variability and the subtropical-tropical cells. J Clim 18:5163-5178

Mann ME, Lees J (1996) Robust estimation of background noise and signal detection in climatic time series. Clim Change 33:409-445

Mann ME, Park J (1996) Greenhouse warming and changes in the seasonal cycle of temperature: model versus observation. Geophys Res Lett 23: 1111-1114.

Mann ME, Lees J, Lall U, Saltzman B (1995) Decadal and secular climate variability: understanding the rise and fall of the Great Salt Lake. Geophys Res Lett 22:937-940

Mantua NJ, Hare SR (2002) The Pacific decadal oscillation. J Oceanogr 58:35-44

Mantua NJ, Hare SR, Zhang Y, Wallace JM, Francis RC (1997) A Pacific interdecadal climate oscillation with impacts on salmon production. Bull Amer Meteor Soc 78:1069-1079
Meinke H, deVoil P, Hammer GL, Power S, Allan R, Stone RC, Folland C, Potgieter A (2005) Rainfall variability at decadal and longer time scales: signal or noise? J Clim 18:89-96

Minobe S (2000) Spatio-temporal structure of the pentadecadal variability over the North Pacific. Prog Oceanogr 47:381-408

Moon YI, Lall U (1996) Large scale atmospheric indices and the Great Salt Lake: interannual and interdecadal variability. J Hydrologic Eng 1:2

Nakamura H, Lin G, Yamagata T (1997) Decadal climate variability in the North Pacific during the recent decades. Bull Amer Meteor Soc 78:2215-2225

Neelin JD (2007) Moist dynamics of tropical convection zones in monsoons, teleconnections, and global warming. In: Schneider T, Sobel AH (eds) The global circulation of the atmosphere. Princeton University Press, Princeton, NJ, pp 267-301

Nigam S, Held IM, Lyons SW (1986) Linear simulation of the stationary eddies in a general circulation model. Part I. The nomountain model. J Atmos Sci 43:2944-2961

Philander SGH (1990) El Niño, La Niña, and the Southern Oscillation. Academic Press, San Diego, CA, p 293

Plumb RA (1985) On the three-dimensional propagation of stationary waves. J Atmos Sci 42:217-229

Rasmusson EM (1991) Observational aspects of ENSO cycle teleconnections. In: Glantz MH, Katz RW, Nicholls N (eds) Teleconnections linking worldwide climate anomalies: scientific basis and societal impact. Cambridge University Press, New York, pp 309-343

Rasmusson EM, Mo K (1993) Linkages between 200-mb tropical and extratropical circulation anomalies during the 1986-1989 ENSO cycle. J Clim 6:595-616

Ruane AC, Roads JO (2008) Dominant balances and exchanges of the atmospheric water cycle in the reanalysis 2 at diurnal, annual, and intraseasonal time scales. J Clim 21:3951-3966

$\mathrm{Su}$ H, Neelin JD (2002) Teleconnection mechanisms for tropical Pacific descent anomalies during El Niño. J Atmos Sci 59:26942712

Takaya K, Nakamura H (2001) A formulation of a phase-independent wave-activity flux for stationary and migratory quasigeostrophic eddies on a zonally varying basic flow. J Atmos Sci 58:608-627

Tourre YM, Rajagopalan B, Kushnir Y, Barlow M, White WB (2001) Patterns of coherent decadal and interdecadal climate signals in the Pacific Basin during the 20th Century. Geophys Res Lett 28:2069

Trenberth KE (1990) Recent observed interdecadal climate changes in the Northern Hemisphere. Bull Amer Meteor Soc 71:988-993

Trenberth KE, Hurrell JW (1994) Decadal atmosphere-ocean variations in the Pacific. Clim Dyn 9:303-319

van Loon H, Meehl GA, Shea DJ (2007) Coupled air-sea response to solar forcing in the Pacific region during northern winter. J Geophys Res 112:D02108.1-D02108.8

Wang B, Chan JCL (2002) How strong ENSO events affect tropical storm activity over the western North Pacific. J Clim 15:16431658

Wang SY, Gillies RR, Jin J, Hipps LE (2009a) Coherence between the Great Salt Lake level and the Pacific quasi-decadal oscillation. J Clim (in press). doi: 10.1175/2009JCLI2979.1

Wang SY, Gillies RR, Jin J, Hipps LE (2009b) Recent rainfall cycle in the Intermountain region as a quadrature amplitude modulation from the Pacific decadal oscillation. Geophys Res Lett 36:L02705. doi:10.1029/2008GL036329

White WB, Liu Z (2008a) Resonant excitation of the quasi-decadal oscillation by the 11-year signal in the Sun's irradiance. J Geophys Res 113:C01002. doi:10.1029/2006JC004057

White WB, Liu Z (2008b) Non-linear alignment of El Niño to the 11-yr solar cycle. Geophys Res Lett 35:L19607. doi:10.1029/ 2008GL034831 
White WB, Tourre YM (2003) Global SST/SLP waves during the 20th century. Geophys Res Lett 30(12):1651. doi:10.1029/ 2003GL017055

White WB, Liu Z, Tourre YM (2003a) Global SST/SLP waves during the 20th century. Geophys Res Lett 30:1651. doi:10.1029/ 2003GL017055

White WB, Liu Z, Barlow M, Dettinger M (2003b) A delayed action oscillator shared by biennial, interannual, and decadal signals in the Pacific Basin. J Geophys Res 108:3070. doi:10.1029/ 2002JC001490

Wu L, Liu Z, Gallimore R, Jacob R, Lee D, Zhong Y (2003) Pacific decadal variability: the tropical Pacific mode and the North Pacific mode. J Clim 16:1101-1120
Xie P, Chen M, Janowiak JE, Arkin PA, Smith TM (2002) Global oceanic precipitation from 1948 to the present: a reconstruction of historical gauge observations. 13th Symposium on Global changes and climate variations. Orlando, FL, 13-17 January 2002

Ye $\mathrm{H}$ (2001) Characteristics of winter precipitation variation over northern central Eurasia and their connections to sea surface temperatures over the Atlantic and Pacific Oceans. J Clim 14:3140-3155

Zhang Y, Wallace JM, Battisti DS (1997) ENSO-like interdecadal variability: 1900-1993. J Clim 10:1004-1020 